\title{
Abnormal Linguistic Lateralization and Sensory Processing in High Functioning Children with Autism Spectrum Conditions
}

\author{
Sonia Martínez-Sanchiss,2, ${ }^{1,2}$ aría Consuelo Bernal ${ }^{3,4}$, Ana Costa5, Marien Gadea ${ }^{1,4}$ \\ ${ }^{1}$ Department of Psychobiology, University of Valencia, Valencia, Spain \\ ${ }^{2}$ Neurodevelopmental Disorders Research Unit, University of Valencia, Valencia, Spain \\ ${ }^{3}$ Department of Social Psychology, University of Valencia, Valencia, Spain \\ ${ }^{4}$ IDOCAL, University of Valencia, Valencia, Spain \\ ${ }^{5}$ Pediatric Neurorehabilitation Unit, Hospital of Manises, Valencia, Spain \\ Email: ${ }^{*}$ Sonia.mtnez-sanchis@uv.es
}

Received 10 July 2014; revised 26 August 2014; accepted 13 September 2014

Copyright (C) 2014 by authors and Scientific Research Publishing Inc.

This work is licensed under the Creative Commons Attribution International License (CC BY).

http://creativecommons.org/licenses/by/4.0/

(c) (7) Open Access

\begin{abstract}
Brain lateralization for language in high-functioning children with autism spectrum conditions (ASC) and sensory processing were explored as a part of a neuropsychological profile. A dichotic listening test and the Luria laterality subtest were administered to all participants (including controls) and the sensory profile test only to the ASC group. The usual right ear advantage was not exhibited by children with ASC and anomalies in auditory filtering were found. The sensory profile of $60 \%$ of the sample was characterized by hypersensitivity to auditory stimuli, hyposensitivity to vestibular information, high emotional reactions to sensory experiences, poor psychosocial coping strategies, high distractibility and inability to interpret body and facial language. Hyper-responsiveness to environmental auditory stimuli was significantly associated with impaired attention. Similarly, non-adaptive responses to sensory quotidian experiences were strongly connected to poor coping strategies. Our results, although preliminary, contribute to emphasizing the importance of including additional assessment methods such as the dichotic listening and the sensory profile questionnaire in the evaluation of cognitive profile in high-functioning children with ASC to plan an individualized psycho-educative intervention.
\end{abstract}

\section{Keywords}

Children, High-Functioning Autism, Linguistic Lateralization, Neuropsychology, Sensory Profile

\footnotetext{
"Corresponding author.
}

How to cite this paper: Martínez-Sanchis, S., Bernal, M.C., Costa, A. and Gadea, M. (2014) Abnormal Linguistic Lateralization and Sensory Processing in High Functioning Children with Autism Spectrum Conditions. Journal of Behavioral and Brain Science, 4, 432-442. http://dx.doi.org/10.4236/jbbs.2014.49042 


\section{Introduction}

People with autism spectrum conditions (ASC) exhibit a neuropsychological pattern which includes some of the behavioral diagnostic markers such as communication impairments and poor social cognition. However, on the whole, the neuropsychological profile is much wider and is characterized by enhanced bottom-up information processing, lack of accurate global integration of data from different sources (top-down processing) and an aberrant sensory profile (hypo-, hyper-responsiveness and seeking behavior). Several authors consider these neuropsychological features to be powerful influencing factors which contribute to communication problems and strong adherence to routines [1]-[4].

Between $60 \%$ and $95 \%$ of people with ASC characteristically exhibit an unusual sensory profile [5]-[8]. In fact, the presence and limiting effect of sensory perception abnormalities have been considered sufficiently important to include them as one of the behavioral markers in the domain of the restricted and repetitive behaviors in the DSM-V [9]. Some authors argue that, because of their high incidence, specificity and their presence along the life span, these sensory symptoms have become good candidates to be added to the nuclear characteristics that define this type of disorder [7] [10]. Hypersensitivity to several sounds, tactile defensiveness or texture food rejections (hypersensitivity to tactile stimuli) are among the first noticeable red flag signs, even prior to those which refer to social interaction deficits. Furthermore, first concerns in parents of children with ASC previous to the diagnosis are also hearing impairment, severe attention deficits or behavioral problems, which could be related to sensory issues. In early childhood, many of these children do not usually respond to their name or follow verbal instructions which could reflect auditory processing alterations such as discrimination, modulation or integration difficulties. Moreover, there are many studies that indicate the existence of anomalies in auditory processing of language and reduced language left lateralization in the majority of individuals with autism (see for a review [11] [12]). Russo, Zecker, Trommer, Chen, and Kraus [13], using evoked potentials, showed how the auditory processing of children with high-functioning ASC in a quiet ambience is identical to that of children with neurotypical development in a noisy environment. Thus, there is evidence of problems in auditory processing of language at the central nervous level. Additionally, they do not benefit from visual cues such as lip reading, which would be a disadvantage in an excessively noisy ambience [14] [15]. Although several works have studied the laterality pattern for speech and language in ASC using EEG, MEG and fMRI, only a few aimed to relate this issue with the sensory processing problems. Orekhova et al. [16] and Stroganova et al. [17] found a strong correlation between the degree of sensory abnormalities, the presence of abnormal arousal, and an atypical hemispheric lateralization of the P100m component of auditory magnetic field response.

Dichotic listening (DL) is the leading behavioral technique for studying laterality and hemispheric asymmetry in healthy controls and clinical conditions. Two paired verbal stimuli, which could be syllables, words or digits, are presented simultaneously, one to the left and one to the right ear. In the non-forced paradigm, subjects are asked to report the syllable best heard. In this condition, an attentional bias to the right auditory space favors a right ear advantage (REA) (superior reports of right ear inputs) which reflects left hemisphere dominance for the control of speech and language and is sustained by a bottom-up processing strategy. Studies in clinical and healthy population showed that DL performance is closely related to the functional integrity of the corpus callosum. Thus, a greater dendritic density in the corpus callosum allows better interhemispheric communication and favors greater verbal capability [18]. In contrast, in some people with ASC there is evidence of a lower volume of the corpus callosum (total and some sub-regions) that correlates with social deficits, repetitive behaviors, sensory abnormalities and an altered pattern of the standard brain lateralization (right-handedness and left-hemisphere dominance for the control of speech and language) [19]-[21]. There is scarce and often contradictory information on DL results in the ASC population. In fact, when compared with controls (who exhibit REA), no differences, no ear preferences or even left ear advantage were found in people with high-functioning ASC [22]-[26]. This disparity in results correlated with the existence of a great heterogeneity in this population, which is evidenced by the use of the term spectrum or "autisms" when referring to autism conditions [27]. Thus, it would be interesting to delimit neuropsychological profiles in order to fit the psycho-educative interventions more efficiently to the individual (the most suitable treatment strategy nowadays). Consequently, the main goal of the present study was to evaluate the brain lateralization for language in a sample of children with ASC (using the DL task) and the sensory profile (especially the auditory perceptions). 


\section{Methods}

\subsection{Participants}

The total sample consisted of thirty-five 6-year-old male children without intellectual disability (cognitive development previously evaluated by the psychologists in each center), hearing loss (assessed through threshold tonal audiometry), or visual impairment.

The ASC group included 17 individuals with diagnoses established by a psychologist and a pediatric neurologist with ASC expertise (according to DSM-IV: Autistic Disorder, Asperger's Syndrome or Pervasive Developmental Disorder, Not Otherwise Specified). Diagnoses were corroborated by the ADOS [28]. These children were recruited from "Psicotrade", a specialized autism center in Valencia (Spain).

An age-matched control group was formed by 18 boys with no evidence of sensory processing impairment, speech/language disorder or learning disabilities. These participants were recruited randomly from "Esclavas de María” school in Valencia (Spain).

\subsection{Procedure}

After collecting written informed parental consent and data about socio-demographic characteristics, an audiometry of each of the subjects was carried out in the speech frequency $(2000 \mathrm{~Hz})$ in order to check that they showed no hearing loss. If they met the audiometric inclusion criteria $(<10 \mathrm{~dB}$ difference between ears at 500 , 1000, 2000, 3000 and $6000 \mathrm{~Hz}$ ), the DL test and the Luria laterality subtest were administered. The sessions lasted around 40 minutes and took place in the morning in a quiet room. Only parents of the ASC children filled in the sensory profile (SP) questionnaire regarding sensory responsiveness exhibited by their sons in quotidian situations. It was administered and interpreted by an occupational therapist specialized in sensory modulation and integration disorders and this professional also gave assistance during the administration of the test. The study was approved by the ethics committee of clinical investigation at the University of Valencia (Spain) and was in accordance with the ethical standards in human research, contained in the Helsinki Declaration of 1975, as revised in 2000 (http://www.wma.net/en/30publications/10policies/b3/index.html).

\subsection{Dichotic Listening}

This standard Consonant-Vowel DL test assesses hemispheric processing and ear preference using variables such as attention, concentration or type of information to be processed [29]. It has been widely validated through different studies [30]-[32] and reaches a test-retest reliability of 0.86 [29]. The children were asked to report only the syllables which were perceived the most clearly after being informed that they would be presented simultaneously to each ear (monosyllables at the standard frequency of the human voice of $2000 \mathrm{~Hz}$ ). The syllables reproduced are TA, KA, GA, PA, BA and DA. Firstly, they are each paired with themselves in order to ensure that the participants are able to recognize them without any problem. All syllables are then paired between themselves, forming 60 pairs (30 initial and homonyms, for example KA-GA, GA-KA). These combinations are made so that each syllable of the pair is heard by each ear, subjects being instructed to verbalize aloud what they hear. Scoring is carried out by taking into account which of the two syllables, presented at the same time, is identified and correctly pronounced.

\subsection{Luria Manual Laterality Test (Standardized for Spanish Children by [33])}

This is a complementary test of the Luria Initial Battery which evaluates motor ability in young children (4 to 6 years old), testing differences in the use of both hands by observing their performance while carrying out activities. This task is based on the neuropsychological Luria-Nebraska Battery (for children aged 12 and older) [34]. It consists of five tasks: writing, drawing, throwing a ball, using scissors, and brushing teeth. The laterality preference quotient is obtained in order to classify subjects according to the preferred hand: (right hand score - left hand score) $\times 10$.

\subsection{Sensory Profile (SP; [35])}

This questionnaire has been proposed by specialists who work with ASC children and provides information about sensory processing difficulties and associated behaviors, detecting which sensory systems could be in- 
volved in functional or dysfunctional performance. It is composed of 125 items rated with a five-point Likert scale (from never to always) and evaluates responses to tactile, olfactory, gustatory, vestibular, auditory and visual stimuli. All items are classified into 14 sections which are grouped into three categories (sensory processing, modulation, and behavioral/emotional responses). Additionally, 9 factors can be identified (see Table 1). The possible scores are organized into three groups (typical performance, probable difference or definite difference) in accordance with the performance of a population sample of children without disabilities ( $n=1307)$; lower scores indicate greater symptoms. Probable difference corresponds to scores greater than $1 \mathrm{SD}$ and less than 2 SD from the mean, and definite differences to scores greater than 2 SD from the normative mean. Internal consistency based upon Cronbach's alpha ranges from 0.47 to 0.91 and the internal validity correlations ranges from 0.25 to 0.76 [40].

\subsection{Statistical Analysis}

Normality (Kolmogorov-Smirnov) and homogeneity of variances (Levene) were checked for all variables.

Table 1. Sensory profile item categories.

A. Sensory Processing

1 Auditory Processing

2 Visual Processing

3 Vestibular Processing

4 Touch Processing

5 Multisensory Processing

6 Oral Sensory Processing

Responses to things heard (e.g., "is distracted or has trouble functioning if there is a lot of noise around")

Responses to things seen (e.g., "is bothered by bright lights after others have adapted to the light")

Responses to movement (e.g., "becomes anxious or distressed when feet leave the ground")

Responses to stimuli that touch the skin (e.g., "becomes irritated by shoes or socks")

Responses to activities that contain a combined sensory experience (e.g., "seems oblivious within an active environment")

Responses to touch and taste stimuli to the mouth (e.g., "limits self to particular food textures/temperatures")

\section{B. Modulation}

7 Sensory Processing Related to Endurance/Tone

Ability to sustain performance

Ability to move effectively

8 Modulation Related to Body Position and Movement

Demonstration of activeness

9 Modulation of Movement Affecting Activity Level

Ability to use body senses to generate emotional responses

10 Modulation of Sensory Input Affecting Emotional Responses Modulation of Visual Input Affecting Emotional Responses and Activity

\section{Behavioural and Emotional Responses}

12 Emotional/Social Responses

Psychosocial coping strategies

13 Behavioural Outcomes of Sensory Processing

Ability to meet performance demands

14 Items Indicating Thresholds for Response

Level of modulation

Factor Scores

1 Sensation Seeking

2 Emotionally Reactive

3 Low Endurance/Tone

4 Oral Sensory Sensitivity

5 Inattention/Distractibility

6 Poor Registration

7 Sensory Sensitivity

8 Sedentary

9 Fine Motor/Perceptual
Interest in and pleasure with sensory experiences in everyday life

Affective responses to sensory experiences in everyday life

Ability to use muscle tone to support self while engaging in activity

Responses to textures, tastes and smells, particularly related to foods

Tendency to be pulled away from activities due to external stimuli, particularly sounds

Tendency to miss cues from sensory experiences in everyday life Level of detection of movement stimuli during everyday life experiences Tendency to be passive during everyday life Ability to use hands 
Means of test scores and standard deviations for the different groups (ASD and control) were calculated. For DL, ANOVA with repeated measures was performed on the correctly reported items according to the design: 2 (Ear input: right vs. left) $\times 2$ (Group: ASD vs. control). Post-hoc DHS Tukey tests were applied when corresponding. Afterwards, the means of the differences and their 95\% confidence intervals were obtained to compare performance between both groups in the tests. Due to the size of the sample, Cohen's d index was calculated to establish the magnitude of the effects of t tests [36]. Finally, the correlation between raw scores of each ear was explored with the Pearson test in each group. Concerning the sensory data, percentages of definite and probable differences regarding typical performance were calculated and Pearson's Correlations between each of the SP components were obtained. SPSS for Windows version 19 was used for data analysis.

\section{Results}

According to the Luria Laterality Test, all subjects included in the sample were totally or preferably righthanded.

\subsection{DL}

Three ASC children were excluded from the DL data due to reluctance to put on the headphones in two of them and the presence of perseverations during the test in one child (e.g. more than 25 "Ka" responses). Thus, the sample for DL data consisted of 14 ASC and 18 control children.

All variables were normally distributed (Kolmogorov-Smirnov test: $\mathrm{p}>0.05$ ) and variance was homogeneous (Levene test: $\mathrm{p}>0.05$ ). The ANOVA based on the children's data showed a significant main effect for the factor Group $(\mathrm{F}(1,30)=62.383$, MSE $=675.22, \mathrm{p}<0.001)$ due to overall better accuracy for the control group (Mean of correctly reported items $=26.58$, range $25.46-27.7$ ) than for the ASC group (Mean of correctly reported items $=20.04$, range $18.77-21.30)$. The main effect for the factor ear was significant $(F(1,30)=5.273$, MSE $=$ 118.08, $\mathrm{p}<0.05$ ), the performance for the right ear was superior (Mean $=24.68$, range $23.06-26.30$ ) than for the left ear $($ Mean $=21.94$, range $20.61-23.27)$. Finally, the Ear $\times$ Group interaction was also significant $(F(1$, $30)=6.738, \mathrm{MSE}=150.89, \mathrm{p}<0.05)$. Post-hoc comparisons revealed that the group of controls showed a REA $(\mathrm{t}(17)=3.947, \mathrm{p}<0.001)$, while the group of ASC did not show this otherwise typical REA ( $\mathrm{t}(13)=-0.185$, $\mathrm{p}$ $=0.856)$. Moreover, controls showed a significantly higher number of correct right ear items than ASC ( $\mathrm{t}(30)=$ $-6.070, p<0.001$ ), as well as a significantly higher number of left ear items than ASC, although to a lesser degree $(\mathrm{t}(30)=-2.652, \mathrm{p}<0.05)$. Figure 1 depicts performance for both ears in each group. Finally, the Pearson correlations showed that the right and left ear scores were inversely correlated for controls $(r=-0.629, p<0.01)$, but not for the group of ASC $(r=-0.162, p=0.579)$.

\subsection{SP}

Taking into account the SP data, more than $50 \%$ of the ASC sample showed differences (probable and definite) with respect to typical performance in inattention/distractibility, auditory and vestibular processing, modulation of sensory input affecting emotional responses, emotional and social responses and, in the emotionally reactive factor (see Figure 2 and Table 2). The sensory profile of the sample was characterized by hypersensitivity to auditory stimuli, hyposensitivity to vestibular information, high emotional reactions to sensory experiences, poor psychosocial coping strategies, high distractibility and inability to interpret body and facial language. Table 3 shows the analysis of total scores from SP categories, which revealed a significant correlation. Inattention/distractibility correlated significantly with auditory $(\mathrm{p}<0.01)$ and vestibular $(\mathrm{p}<0.05)$ processing modalities. Additionally, a significant correlation was found between the last two $(\mathrm{p}<0.01)$. Similarly, modulation of sensory input affecting emotional responses, emotional/social responses, and emotionally reactive variables correlated significantly between one another $(\mathrm{p}<0.01$ and $\mathrm{p}<0.05)$. All these correlations indicate that if a lower score was found in one of these modalities, a lower score was more likely to be found in the other.

\section{Discussion}

The main goal of the present study was to evaluate the sensory profile and language lateralization using DL in a sample of high functioning boys with ASC in comparison to typically developing age-matched children. Although neuroimaging techniques have revealed an abnormal linguistic lateralization pattern in the majority of 


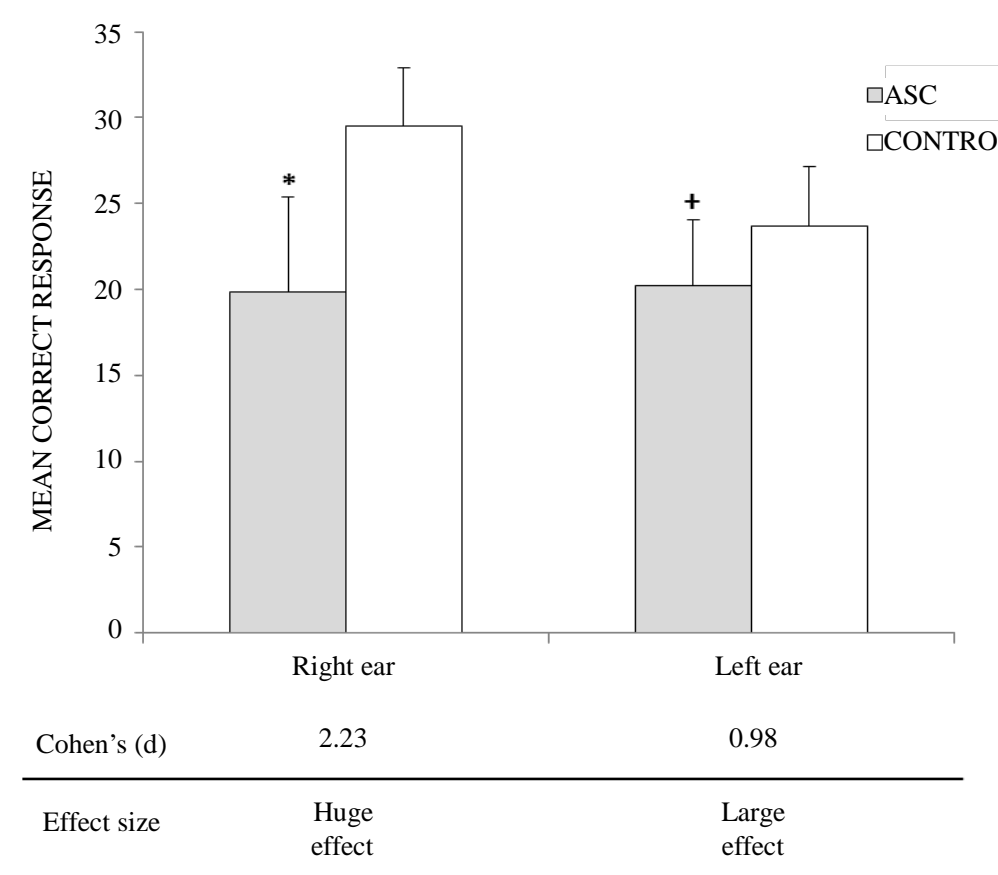

Figure 1. Differences between high-functioning children with ASC and controls in the mean correct response of right and left ear (Means and Standard Errors provided). ${ }^{*} \mathrm{p}<0.001,{ }^{+} \mathrm{p}<0.05$.

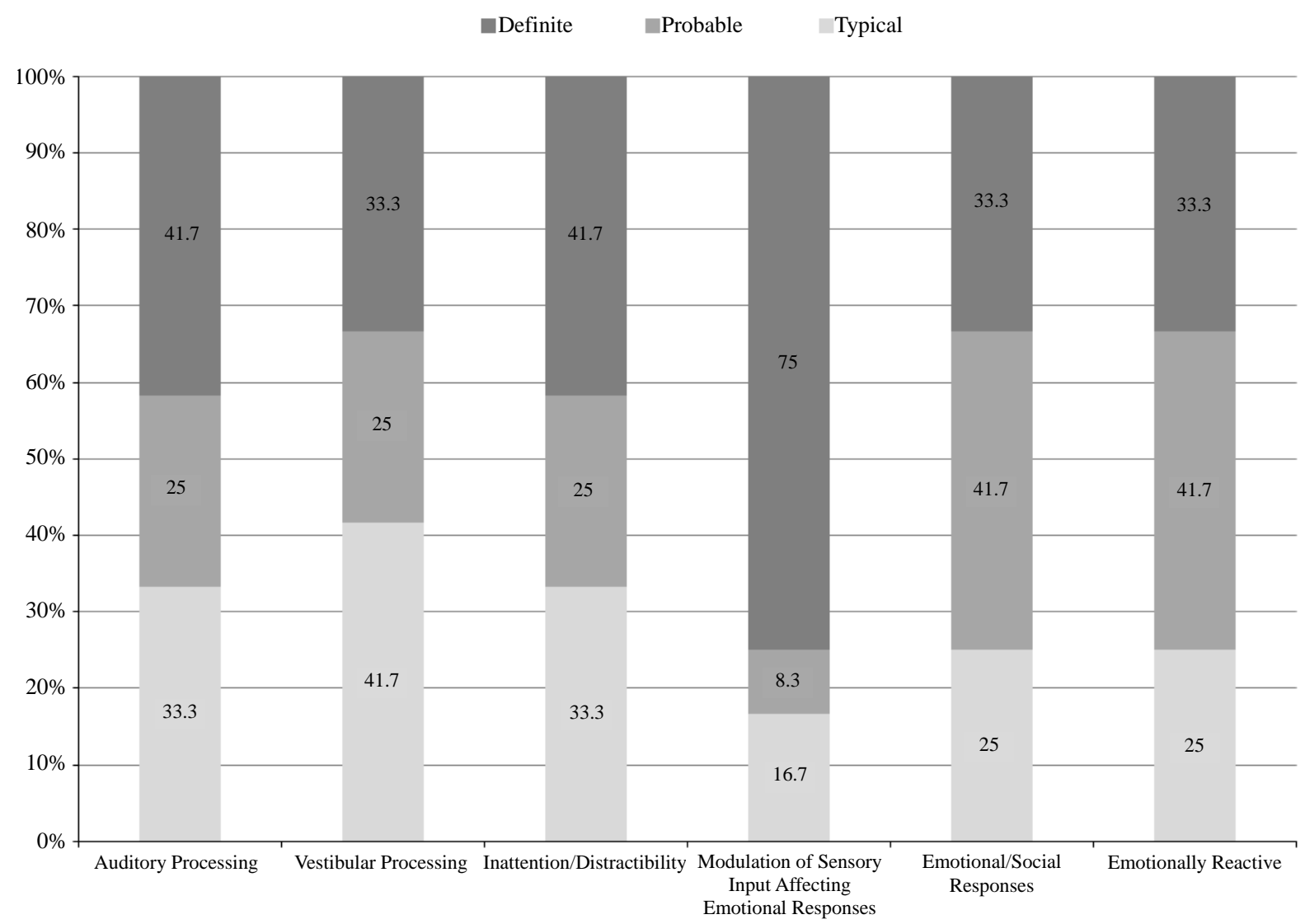

Figure 2. Percentage of children with ASC showing typical performance, probable differences (1 SD or more from the normative mean) and definite differences (2 SD or more from the normative mean) in sensory processing. 
Table 2. Percentages of children who always or frequently displayed behaviors on the SP.

\begin{tabular}{|c|c|}
\hline Item & $\%$ \\
\hline \multicolumn{2}{|l|}{ Auditory Processing } \\
\hline $\begin{array}{l}\text { 1. Responds negatively to unexpected or loud noises (for example, cries or hides at noise from vacuum cleaner, } \\
\text { dog barking, hair dryer) }\end{array}$ & 33.3 \\
\hline 2. Holds hands over ears to protect ears from sound & 16.7 \\
\hline 3. Has trouble completing tasks when the radio is on & 25.0 \\
\hline 4. Is distracted or has trouble functioning if there is a lot of noise around & 50.0 \\
\hline 5. Can't work with background noise (for example, fan, refrigerator) & 16.7 \\
\hline 6. Appears to not hear what you say (for example, does not "tune-in" to what you say, appears to ignore you) & 25.0 \\
\hline 7. Doesn't respond when name is called but you know the child's hearind is OK & 16.7 \\
\hline 8. Enjoys strange noises/seeks to make noise for noise's sake & 25.0 \\
\hline \multicolumn{2}{|l|}{ Vestibular Processing } \\
\hline 18. Becomes anxious or distressed when feet leave the ground & 8.3 \\
\hline 19. Dislikes activities where head is upside down (for example, somersaults, roughhousing) & 16.7 \\
\hline 20. Avoids playground equipment or moving toys (for example, swing set, merry-go-round) & 8.3 \\
\hline 21. Dislikes riding in a car & 0.0 \\
\hline 22. Holds head upright, even when bending over or leaning (for example, maintains a rigid position/posture during activity) & 0.0 \\
\hline 23. Becomes disoriented after bending over sink or table (for example, falls or gets dizzy) & 0.0 \\
\hline 24. Seeks all kinds of movement and this interferes with daily routines (for example, can’t sit still, fidgets) & 33.3 \\
\hline 25. Seeks out all kinds of movement activities (for example, being whirled by adult, merry-go-rounds, playground equipment) & 25.0 \\
\hline 26. Twirls/spins self frequently throughout the day (for example, likes dizzy feeling) & 8.3 \\
\hline 27. Rocks unconsciously (for example, while watching TV) & 0.0 \\
\hline 28. Rocks in desk/chair/on floor & 0.0 \\
\hline \multicolumn{2}{|l|}{ Modulation of Sensory Input Affecting Emotional Responses } \\
\hline 92. Needs more protection from life than other children (for example, defenseless physically or emotionally) & 41.7 \\
\hline 93. Rigid rituals in personal hygiene & 25.0 \\
\hline 94. Is overly affectionated with others & 41.7 \\
\hline 95. Doesn't perceive body language or facial expressions (for example, unable to interpret) & 50.0 \\
\hline \multicolumn{2}{|l|}{ Emotional/Social Responses } \\
\hline 100. Seems to have difficulty liking self (for example, low self-esteem) & 16.7 \\
\hline 101. Has trouble "growing up" (for example, reacts immaturely to situations) & 50.0 \\
\hline 102. Is sensitive to criticisms & 50.0 \\
\hline 103. Has definite fears (for example, fears are predictable) & 41.7 \\
\hline 104. Seems anxious & 33.3 \\
\hline 105. Displays excessive emotional outbursts when unsuccessful at a task & 50.0 \\
\hline 106. Expresses feeling like a failure & 16.7 \\
\hline 107. Is stubborn or uncooperative & 33.3 \\
\hline 108. Has temper tantrums & 25.0 \\
\hline 109. Poor frustration tolerance & 33.3 \\
\hline 110. Cries easily & 41.7 \\
\hline 111. Overly serious & 8.3 \\
\hline 112. Has difficulty making friends (for example, does not interact or participate in gropu play) & 33.3 \\
\hline 113. Has nightmares & 0.0 \\
\hline 114. Has fears that interfere with daily routine & 25.0 \\
\hline 115. Doesn’t have a sense of humor & 16.7 \\
\hline 116. Doesn’t express emotions & 0.0 \\
\hline \multicolumn{2}{|l|}{ Emotionally Reactive } \\
\hline 121. Has difficulty tolerating changes in plans and expectations & 16.7 \\
\hline 122. Has difficulty tolerating changes in routines & 25.0 \\
\hline \multicolumn{2}{|l|}{ Inattention/Distractibility } \\
\hline 48. Has difficulty paying attention & 50.0 \\
\hline 49. Looks away from tasks to notice all actions in the room & 58.3 \\
\hline
\end{tabular}

Note: Bold items are those with "always" or "frequently" reported behaviors by $50 \%$ or more of the caregivers of children with ASC. Emotionally Reactive factor also includes items 92, 100, 101, 102, 103, 104, 105, 106, 107, 108, 109, 110, 111 and 112. Inattention/Distractibility factor also includes items 3, 4, 5, 6 and 7. 
Table 3. Pearson correlation coefficients among sensory variables ( $\left.{ }^{* *} \mathrm{p}<0.01, \stackrel{*}{\mathrm{p}}<0.05\right)$.

\begin{tabular}{lcccc}
\hline & Vestibular & Inattention/Distractibility & Emotionally Reactive & Emotional/Social Responses \\
\hline Auditory Processing & $0.774^{* *}$ & $0.913^{* *}$ & \\
Vestibular Processing & & $0.616^{*}$ & \\
Emotional/Social Responses & & $0.959^{* *}$ & $0.778^{* *}$ \\
$\begin{array}{l}\text { Modulation of Sensory Input } \\
\text { Affecting Emotional Responses }\end{array}$ & & $0.655^{*}$ \\
\hline
\end{tabular}

persons with ASC, only a few studies have been carried out in high-functioning children with ASC. Additionally, scarce literature has been published in the ASC field using the DL task, which has been proved to be a reliable non-invasive instrument to evaluate language laterality and hemisphere functioning in typically developing controls and clinical conditions [37].

Contrary to results found in controls, individuals from the ASC group did not exhibit either the REA or the significant negative correlation between data from both ears, which could indicate an abnormal linguistic lateralization pattern (either bilateral or mixed processing dominance) and a lack of interhemispheric integration of the information. The latter was found in fathers but not mothers of this ASC sample, supporting the existence of a certain genetic vulnerability [38]. In a recent systematic review, Lindell and Hudry [11] have stated that contradictory results found in the previous studies using DL in children with ASC could be due to the sample size. For these authors, a sample of 19 subjects is enough to power the analysis as in the study carried out by Prior and Bradshaw [26], although up to date there has been no replication. In the current study, size effect was calculated (Cohen's d and r) and revealed that the differences between groups were large or huge (see Figure 1). Nevertheless, it would be convenient in future research to increase the sample and the age interval, and also include other comparison groups with sensory modulation difficulties without ASC.

Cardinale, Shih, Fishman, Ford, and Müller [39] have examined hemispheric asymmetry of several functional networks in a group of high-functioning children and adolescents ( 9 - 18 years old) and found an atypical rightward asymmetry not only in the auditory network but also in components involved in visual, sensorimotor, visuospatial, executive and attentional processing. These findings support the strong association between abnormal linguistic lateralization and atypical sensorimotor processing in ASC. Ludlow et al. [40] in high-functioning children with ASC found that the greater the sensory disturbances (especially auditory sensitivity) the worse the auditory processing during automatic language tasks (using event-related potentials to meaningless and meaningful speech stimuli).

In concordance with previous studies, modulation disorders in more than one sensory channel were found in our sample. The sensory profile of our sample of children with ASC was characterized by auditory hypersensitivity, vestibular hyposensitivity and high distractibility. This profile is similar to the postural inattentive subtype, one of the four subtypes described by Lane et al. [41], and is characterized by an under-responsive seeking sensation as well as difficulties in postural processing and auditory filtering. The sensory symptoms are frequently associated with increased autism severity and contribute to social interaction [41] [42]. Hence, although people with high-functioning ASC have no intellectual disability, their sensory quotidian difficulties should not be underestimated considering their impact on communication and social cognition [43]. One of the main recent associations between sensory disturbances and the core ASC features is sensory hyper-responsiveness and communication competence [41]. Taking into account this relationship, we could conclude that as soon as the children are overloaded by auditory information, especially when it is verbal, attention could be seriously impaired. At vestibular level, many people within the autistic spectrum are hypo-responsive and seek this type of stimulation by spinning and rocking themselves, and in our sample this pattern seems to be related to the distractibility and auditory hyper-responsiveness exhibited [42]. Similarly, the intense affective responses to quotidian sensory experiences were closely associated with poor coping strategies and impairments in the interpretation of body and facial language, as revealed by the correlations.

\section{Conclusion}

To conclude, it could be said that a comprehensive neuropsychological evaluation in the ASC population would 
allow professionals to build a profile about cognitive deficits and strengths in order to orientate the intervention from a multidisciplinary approach, including not only psychologists, pedagogues or speech therapists but also occupational therapists. Moreover, in terms of research, it would allow the exploration of variations throughout the spectrum. The collection of data referring to language lateralization and the sensory profile would allow professionals to design individualized intervention protocols including sensory-based therapies [44], and psycho-educative strategies based on structured teaching relying on visual information like the TEACCH program (Treatment and Education of Autistic and related Communication-handicapped Children [45] [46]).

\section{Acknowledgements}

The authors especially wish to thank all the children who participated in the study and their families. They would also like to express their gratitude to staff from "Esclavas de María” school, "Psicotrade” center and Project Autism Association (ASPAU) for their collaboration.

\section{References}

[1] Donnellan, A.M., Hill, D.A. and Leary, M.R. (2013) Rethinking Autism: Implications of Sensory and Movement Differences for Understanding and Support. Frontiers in Integrative Neuroscience, 6, 124. http://dx.doi.org/10.3389/fnint.2012.00124

[2] Hilton, C., Graver, K. and LaVesser, P. (2007) Relationship between Social Competence and Sensory Processing in Children with High Functioning Autism Spectrum Disorders. Research in Autism Spectrum Disorders, 1, 164-173. http://dx.doi.org/10.1016/j.rasd.2006.10.002

[3] O’Connor, K. and Kirk, I. (2008) Brief Report: Atypical Social Cognition and Social Behaviours in Autism Spectrum Disorder: A Different Way of Processing Rather Than an Impairment. Journal of Autism Developmental Disorders, 38, 1989-1997. http://dx.doi.org/10.1007/s10803-008-0559-5

[4] Reynolds, S., Bendixen, R., Lawrence, T. and Lane, S.J. (2011) A Pilot Study Examining Activity Participation, Sensory Responsiveness, and Competence in Children with High Functioning Autism Spectrum Disorder. Journal of Autism and Developmental Disorders, 41, 1496-1506. http://dx.doi.org/10.1007/s10803-010-1173-x

[5] Baker, A.E.Z., Lane, A., Angley, M.T. and Young, R.L. (2008) The Relationship between Sensory Processing Patterns and Behavioural Responsiveness in Autistic Disorder: A Pilot Study. Journal of Autism and Developmental Disorders, 38, 867-875. http://dx.doi.org/10.1007/s10803-007-0459-0

[6] Baranek, G.T., Boyd, B., Poe, M.D., David, F.J. and Watson, R.L. (2007) Hyperresponsive Sensory Patterns in Young Children with Autism, Developmental Delay and Typical Development. American Journal of Mental Retardation, 112, 233-245. http://dx.doi.org/10.1352/0895-8017(2007)112\%5B233:HSPIYC\%5D2.0.CO;2

[7] Ben-Sasson, A., Hen, L., Fluss, R., Cermak, S.A., Engel-Yeger, B. and Gal, E. (2009) A Meta-Analysis of Sensory Modulation Symptoms in Individuals with Autism Spectrum Disorders. Journal of Autism Developmental Disorders, 39, 1-11. http://dx.doi.org/10.1007/s10803-008-0593-3

[8] Tomcheck, S.D. and Dunn, W. (2007) Sensory Processing in Children with and without Autism: A Comparative Study Using the Short Sensory Profile. American Journal of Occupational Therapy, 61, 190-200. http://dx.doi.org/10.5014/ajot.61.2.190

[9] American Psychiatric Association (APA) (2013) DSM-V Diagnostic and Statistical Manual of Mental Disorders. 5th Edition, American Psychiatric Association, Washington, DC.

[10] Tavassoli, T., Miller, L.J., Schoen, S.A., Nielsen, D.M. and Baron-Cohen, S. (2014) Sensory Over-Responsivity in Adults with Autism Spectrum Conditions. Autism, 18, 428-432. http://dx.doi.org/10.1177/1362361313477246

[11] Lindell, A.K. and Hudry, K. (2013) Atypicalities in Cortical Structure, Handedness, and Functional Lateralization for Language in Autism Spectrum Disorders. Neuropsychology Review, 23, 257-270. http://dx.doi.org/10.1007/s11065-013-9234-5

[12] Nielsen, J.A., Zielinski, B.A., Fletcher, P.T., Alexander, A.L., Lange, N., Bigler, E.D., Lainhart, J.E. and Anderson, J.S. (2014) Abnormal Lateralization of Functional Connectivity between Language and Default Mode Regions in Autism. Molecular Autism, 5, 8. http://dx.doi.org/10.1186/2040-2392-5-8

[13] Russo, N., Zecker, S., Trommer, B., Chen, J. and Kraus, N. (2009) Effects of Background Noise on Cortical Encoding of Speech in Autism Spectrum Disorders. Journal of Autism Developmental Disorders, 39, 1185-1196. http://dx.doi.org/10.1007/s10803-009-0737-0

[14] Bonneh, Y.S., Levanon, Y., Dean-Pardo, O., Lossos, L. and Adini, Y. (2011) Abnormal Speech Spectrum and Increased Pitch Variability in Young Autistic Children. Frontiers in Human Neuroscience, 4, 237. 
http://dx.doi.org/10.3389/fnhum.2010.00237

[15] Iarocci, G., Rombough, A., Yager, J., Weeks, D.J. and Chua, R. (2010) Visual Influences on Speech Perception in Children with Autism. Autism, 14, 305-320. http://dx.doi.org/10.1177/1362361309353615

[16] Orekhova, E.V., Tsetlin, M.M., Butorina, A.V., Novikova, S.I., Gratchev, V.V., Sokolov, P.A., Elam, M. and Stroganova, T.A. (2012) Auditory Cortex Responses to Clicks and Sensory Modulation Difficulties in Children with Autism Spectrum Disorders (ASD). PloS ONE, 7, e39906. http://dx.doi.org/10.1371/journal.pone.0039906

[17] Stroganova, T.A., Kozunov, V.V., Posikera, I.N., Galuta, I.A., Gratchev, V.V. and Orekhova, E.V. (2013) Abnormal Pre-Attentive Barousal in Young Children with Autism Spectrum Disorder Contributes to Their Atypical Auditory Behavior: An ERP Study. PloS ONE, 8, e69100. http://dx.doi.org/10.1371/journal.pone.0069100

[18] Westerhausen, R. and Hugdahl, K. (2008) The Corpus Callosum in Dichotic Listening Studies of Hemispheric Asymmetry: A Review of Clinical and Experimental Evidence. Neuroscience and Biobehavioral Reviews, 32, 1044-1054. http://dx.doi.org/10.1016/j.neubiorev.2008.04.005

[19] Hardan, A.Y., Pabalan, M., Gupta, N., Bansal, R., Melhem, N.M., Fedorov, S., Keshavan, M.S. and Minshew, N.J. (2009) Corpus Callosum Volume in Children with Autism. Psychiatry Research: Neuroimaging, 174, 57-61. http://dx.doi.org/10.1016/j.pscychresns.2009.03.005

[20] Just, M.A., Cherkassky, V.L., Keller, T.A., Kana, R.K. and Minshew, N.J. (2007) Functional and Anatomical Cortical Underconnectivity in Autism: Evidence from an fMRI Study of an Executive Function Task and Corpus Callosum Morphometry. Cerebral Cortex, 17, 951-961. http://dx.doi.org/10.1093/cercor/bhl006

[21] Kana, R.K., Keller, T.A., Cherkassky, V.L., Minshew, N.J. and Just, M.A. (2006) Sentence Comprehension in Autism: Thinking in Pictures with Decreased Functional Connectivity. Brain, 129, 2484-2493. http://dx.doi.org/10.1093/brain/awl164

[22] Arnold, G. and Schwartz, G.E. (1983) Hemispheric Lateralization of Language in Autistic and Aphasic Children. Journal of Autism and Developmental Disorders, 13, 129-139. http://dx.doi.org/10.1007/BF01531814

[23] Blackstock, E.G. (1978) Cerebral Asymmetry and the Development of Early Infantile Autism. Journal of Autism and Childhood Schizophrenia, 8, 339-353. http://dx.doi.org/10.1007/BF01539636

[24] Hayashi, M., Takamura, I., Kohara, H. and Yamazaki, K. (1989) A Neurolinguistic Study of Autistic Children Employing Dichotic Listening. The Tokai Journal of Experimental and Clinical Medicine, 14, 339-345.

[25] McCann, B.S. (1982) Hemispheric Asymmetries and Early Infantile Autism. Journal of Autism and Developmental Disorders, 11, 401-411. http://dx.doi.org/10.1007/BF01531615

[26] Prior, M.R. and Bradshaw, J.L. (1979) Hemisphere Functioning in Autistic Children. Cortex, 15, 73-81. http://dx.doi.org/10.1016/S0010-9452(79)80008-8

[27] Coleman, M. and Gillberg, C. (2012) The Autisms. Oxford University Press, New York.

[28] Lord, C., Rutter, M., DiLavore, P.C. and Risi, S. (1999) Autism Diagnostic Observation Schedule-WPS (ADOS-WPS). Western Psychological Services, Los Angeles.

[29] Gadea, M., Gómez, C. and Espert, R. (2000) Test-Retest Performance for the Consonant-Vowel Dichotic Listening Test with and without Attentional Manipulations. Journal of Clinical and Experimental Neuropsychology, 22, 793-803. http://dx.doi.org/10.1076/jcen.22.6.793.959

[30] Hugdahl, K. (1995) Dichotic Listening: Probing Temporal Lobe Functional Integrity. In: Davidson, R.J. and Hugdahl, K., Eds., Brain Asymmetry, MIT Press, Cambridge, 123-156.

[31] Hugdahl, K., Carlsson, G., Uvebrant, P. and Lundervold, A.J. (1997) Dichotic-Listening Performance and Intracarotid Injections of Amobarbital in Children and Adolescents. Preoperative and Postoperative Comparisons. Archives of Neurology, 54, 1494-1500. http://dx.doi.org/10.1001/archneur.1997.00550240046011

[32] Hugdahl, K., Westerhausen, R., Alho, K., Medvedev, S., Laine, M. and Hämäläïnen, H. (2009) Attention and Cognitive Control: Unfolding the Dichotic Listening Story. Scandinavian Journal of Psychology, 50, 11-22. http://dx.doi.org/10.1111/j.1467-9450.2008.00676.x

[33] Manga, D. and Ramos, F. (2006) Luria Inicial. Evaluación neuropsicológica en la edad preescolar. Publicaciones de Psicología Aplicada, TEA Ediciones, Madrid.

[34] Golden, C.J., Hammeke, T.A. and Purisch, A.D. (1978) Diagnostic Validity of a Standardized Neuropsychological Battery Derived from Luria’s Neuropsychological Tests. Journal of Consulting and Clinical Psychology, 46, 1258-1265. http://dx.doi.org/10.1037/0022-006X.46.6.1258

[35] Dunn, W. (1999) Sensory Profile. The Psychological Corporation, San Antonio.

[36] Cohen, J. (1988) Statistical Power Analysis for the Behavioral Sciences. 2nd Edition, Erlbaum, Mahwah.

[37] Hugdahl, K. (2011) Fifty Years of Dichotic Listening Research-Still Going and Going and... Brain and Cognition, 
76, 211-213. http://dx.doi.org/10.1016/j.bandc.2011.03.006

[38] Martínez-Sanchis, S., Bernal, M.C., Cortés, R. and Gadea, M. (2014) Language Laterality, Handedness and Empathy in a Sample of Parents of Children with Autism Spectrum Disorder. Psicothema, 26, 17-20.

[39] Cardinale, R.C., Shih, P., Fishman, I., Ford, L.M. and Müller, R.A. (2013) Pervasive Rightward Asymmetry Shifts of Functional Networks in Autism Spectrum Disorder. JAMA Psychiatry, 70, 975-982. http://dx.doi.org/10.1001/jamapsychiatry.2013.382

[40] Ludlow, A., Mohr, B., Whitmore, A., Garagnani, M., Pulvermüller, F. and Gutierrez, R. (2014) Auditory Processing and Sensory Behaviours in Children with Autism Spectrum Disorder as Revealed by Mismatch Negativity. Brain and Cognition, 86, 55-63. http://dx.doi.org/10.1016/j.bandc.2014.01.016

[41] Lane, A.E., Molloy, C.A. and Bishop, S.L. (2014) Classification of Children with Autism Spectrum Disorder by Sensory Subtype: A Case for Sensory-Based Phenotypes. Autism Research, 7, 323-333. http://dx.doi.org/10.1002/aur.1368

[42] Lane, A.E., Dennis, S.J. and Geraghty, M.E. (2011) Brief Report: Further Evidence of Sensory Subtypes in Autism. Journal of Autism Developmental Disorders, 41, 826-831. http://dx.doi.org/10.1007/s10803-010-1103-y

[43] Ausderau, K., Sideris, J., Furlong, M., Little, L.M., Bulluck, J. and Baranek, G.T. (2013) National Survey of Sensory Features in Children with ASD: Factor Structure of the Sensory Experience Questionnaire (3.0). Journal of Autism and Developmental Disorders, 44, 915-925. http://dx.doi.org/10.1007/s10803-013-1945-1

[44] Iwanaga, R., Honda, S., Nakane, H., Tanaka, K., Toeda, H. and Tanaka, G. (2014) Pilot Study: Efficacy of Sensory Integration Therapy for Japanese Children with High-Functioning Autism Spectrum Disorder. American Journal of Occupational Therapy, 21, 4-11. http://dx.doi.org/10.1002/oti.1357

[45] Mesibov, G.B., Shea, V. and Schopler, E. (2005) The TEACCH Approach to Autism Spectrum Disorders. Springer, New York.

[46] Mesibov, G.B. and Shea, V. (2010) The TEACCH Program in the Era of Evidence-Based Practice. Journal of Autism Developmental Disorders, 40, 570-579. http://dx.doi.org/10.1007/s10803-009-0901-6 
Scientific Research Publishing (SCIRP) is one of the largest Open Access journal publishers. It is currently publishing more than 200 open access, online, peer-reviewed journals covering a wide range of academic disciplines. SCIRP serves the worldwide academic communities and contributes to the progress and application of science with its publication.

Other selected journals from SCIRP are listed as below. Submit your manuscript to us via either submit@scirp.org or Online Submission Portal.
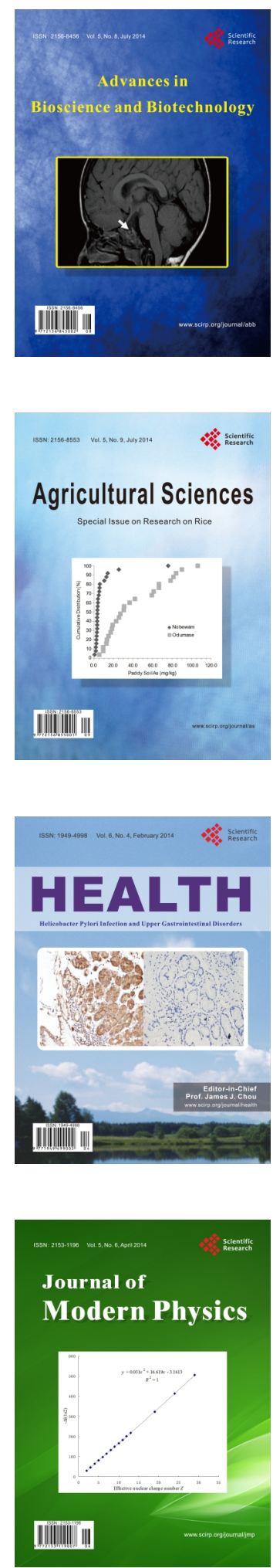
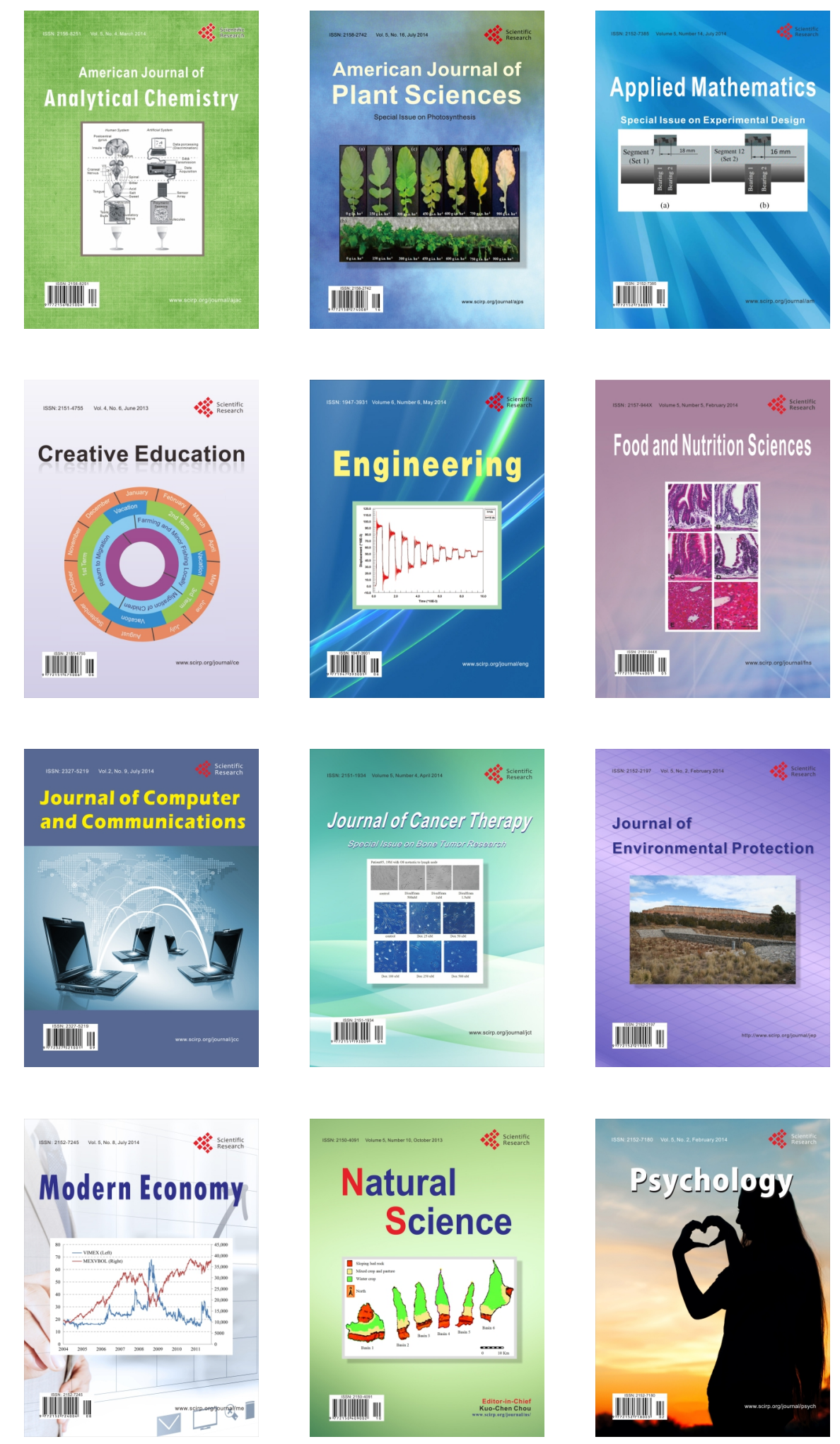